\title{
An Assessment of Organizational Capabilities for ERP Implementation in SMEs: A Governance Model for IT Success using a Resource-based Approach
}

\author{
Dr. Houcine Chatti ${ }^{1}$, Dr. Evan Asfoura ${ }^{2}$ \\ Dar Al Uloom University \\ Riyadh, Saudi Arabia
}

\author{
Dr. Gamal Kassem ${ }^{3}$ \\ German University \\ Cairo, Egypt
}

\begin{abstract}
One of the most coveted technological innovations is the increasing use of Integrated Management Software (ERP) since the early 1990s. ERP is considered a powerful reengineering tool that profoundly transforms a company's business processes and changes the way to conduct reengineering projects and implement new software. The significant number of failures as reported in the literature on ERP emphasizes the fact that some companies may not realize the expected benefits. This result becomes particularly significant in the case of SMEs which have their own contingencies in addition to the scarcity of resources which may, in turn, lead to the failure of ERP implementation. This leads initially to ask, in one hand, about the variables of success of this innovation i.e. the determinants of the techno-organizational innovation; and on the other hand, about the existence of a model of dependences analysis between these determinants and their success as perceived by the management. The current empirical research is carried out in 92 companies having adopted a whole or a part of their IS with an ERP system. Having analyzed the data collected via a questionnaire, and applying the method of structural equation (MSE), results prove the existence of one "general fit" between the data and the supposed relations of causality.
\end{abstract}

Keywords-ERP success; systemic approach; quantitative study; structural equation modelling

\section{INTRODUCTION}

ERP is considered a powerful reengineering tool that profoundly transforms a company's business processes and changes the way to conduct reengineering projects and implement new software. Many large companies are attracted by this IT because of their desire to evolve their architecture, but also the processes supporting the business system [1]. The 1st generation ERP was thus designed to process management information in real time and networked within the same organization. It helped streamline and integrate business processes and information flows, creating synergies between the company's resources. The 2nd generation system now offers a platform for reengineering and internal integration of business processes. It enables new models of interorganizational integration by industry to be envisaged, as is the case in highly competitive sectors in which SMEs operate. The deployment of this IT is thus part of a context of governance that has been the subject of very little work.

Companies that choose an ERP face a double challenge: first, to control their choice [2], and second, to implement and use it with certain guarantees of success. In both cases, their managers must decide with knowledge of the risks of failure incurred [3], while ensuring, as Davenport [4] postulates, that this technology is thought out and used to produce real added value for the company. Thus, the interest in the failure, or conversely the success, of an ERP is justified in research work [5], but also by the specialized press, by the fact that the expected returns on this investment are difficult to quantify in terms of net results in the short or medium term, i.e. immediate direct benefits [6].

Investment in this enterprise software package is now more a standard for integrating management systems and as a strategic lever for intra versus inter-organizational collaboration [7]. Indeed, this standard makes it possible to coordinate operations in business networks by facilitating long-term relationships. It facilitates the integration of the management systems of SMEs belonging to the same industry or operating in the same market [8]. Marketplaces by industry are thus intended to support this collaboration by emphasizing the importance of being able to interconnect different management systems, whether CRM, B2B or SCM, to the company's ERP system.

This is particularly true for SMEs that have their own contingencies and limited resources, making them vulnerable to the failure of an ERP implementation. This observation leads us to assign a double objective to this work. Firstly, to identify the organizational and technological capabilities that are useful for accepting a technological innovation such as ERP and facilitating its success; and secondly, to propose a model for analyzing the effects of these capabilities on ERP success, in the case of SMEs. These objectives are therefore part of a general questioning on the respective and simultaneous influence (1) of specific and critical organizational capacities or resources (such as the capacities of the management, the IS and the software package, the implementation project,...); and (2) of capacities to innovate and implement this technological solution (such as the capacities to accept and integrate it in the management practices), on the performance of the company. This issue of evaluating the causes of an ERP's success, and the questions that emerge from this paper, firstly to identify the determinants of success, and secondly to formulate an original model for predicting success, are part of a general ERP governance research context [9]. 


\section{EVAluAting ERP SucCESS}

\section{A. The Theoretical Context of the Evaluation}

Evaluating the success of an ERP leads to dealing, from a theoretical point of view, with its governance, and finds its justification in the numerous studies [10] which aim to protect organizations from the risks of failure an implementation of this IT. In this sense, it is about producing stable, conceptually invariant knowledge and models that support proactive investment decisions. The evaluation thus responds to the basis of the model of a "logical platform" for developing the governance activities of an IT, formulated by Schwars and Hirscheim [11]. It concerns, according to Sambamurthy and Zmud [12], “contingency forces" (e.g. management and strengthening of organizational and technological capacities). It is these strengths that allow organizations to organize the governance mode of an ERP, by identifying, on the one hand, the critical possibilities or capacities that this technology offers (eg resources and creation of assets), and by designing, on the other hand, a management model (ie a relational versus integrated business architecture) capable of supporting its use and consistent with the strategic vision.

Two theoretical approaches, independent but complementary, are mobilized to identify the contingency forces which will be declined, in this work, in terms of resources or organizational and technological capacities in relation to the problem posed by the evaluation of the perceived success of an ERP. The first one borrows from the field of work on IT strategic planning, the hypothesis of the existence of determinants or key factors of success of an IT project. It is therefore a question of identifying certain resources, availabilities or organizational capacities that must be present when integrating the management system with an ERP. The second takes from the field of work on the diffusion of innovation the hypothesis that the process of adopting an IT depends on its intrinsic characteristics, which can also influence its success. It is therefore a question of identifying properties of this management process that transforms the existing organization as a result of the introduction of new technological capabilities.

To sum up, each of these two approaches contributes, with its own deterministic approach, to questioning the causes of the success of ERPs and the conditions of their governance, placing greater emphasis, as Barua and Mukhopadhyay [13] mention, on the behavioral and organizational capacities of organizations, whether economic or financial. The confrontation of these two approaches supports the deterministic research framework that has provided a large body of work over the last decade [6][14]. Much of this work has mobilized "behaviourist" models for evaluating IT success, very often derived from Davis [15] Technology Acceptance Model (TAM), or DeLone and McLean's [16] Adoption Model. The postulated complementarity of these approaches is in line with the theoretical format of these reference models and suggests, below, a justification of the theoretical choices and a generic approach for investigating research concepts based on a resource-based view of evaluating the success of ERPs.

\section{B. The Theoretical Framework of Research}

The theoretical perspectives mentioned are supported, initially, by the choice of strategic alignment models and organizational innovation, whose foundations, organizational "fit" and "adoption" of ERP, are established by multiple contingencies (e.g. managerial, organizational, strategic and technological). Each of these models supports an approach to evaluating ERP success - studies on "fit" seek to find interdependencies between various contingencies or capabilities that explain the success of this IT; those on "adoption" seek to identify the optimal conditions or capabilities for its adaptation to individuals and the organization, which also explain its success. The complementarity of the contributions of these two models is taken up by numerous works dealing with a resource-based approach (RBA) - this complementarity is addressed by the formulation of a systemic process of capacity transformation. The study of this process requires, in a second step, to formalize the structure of a theoretical working meta-model.

The Strategic IT Alignment Model, postulated by the founding model of Henderson and Venkatraman [17], is certainly the most appropriate model in the field of "ERP strategy" because it provides a formal structure for analyzing the key success factors. This structure, based on a study of the multiple contingencies of IT governance, is particularly well suited to work dealing with ERP performance, its direct or induced benefits, and the identification of its CSFs [18]. This model conceptually supports the involvement of the resources (managerial and technological) that an organization must have at its disposal to plan the development of an IT. The Strategic IT Alignment Model, which has been at the origin of numerous studies aimed at determining the impact of IT on organizational performance, is based in particular on the concepts of strategic integration and functional integration [19]. Strategic integration suggests an alignment between the external and internal business environment, while functional integration suggests the synergy between business processes and the IT used. The implementation of an ERP, leading to the integration of the organization's IT applications, limits here the theoretical investigation to functional integration alone. Only this integration makes it possible to apprehend the managerial, organizational and technological capacities required to properly align business processes (management model) with technical processes (integrated architecture model).

The theoretical framework for the diffusion of innovation, postulated by the founding model of Rogers [20], is also the one that has become established in the field of research on organizational change with IT, because it makes explicit the conditions for acceptance/adoption of an organizational innovation, and that of the management or resource allocation process that improves the contribution of ITs to the organizational performance of the firm. The original innovation adoption model, which has been the source of a great deal of work on IT, such as EDI or ERPs [21], emphasizes the perceived characteristics of an IT to explain the probability and speed of diffusion of innovation within the social system. Perceived characteristics play a fundamental 
role in the persuasion phase, during which the decision unit assesses the appropriateness of adopting or not adopting the technological innovation. In the case of ERPs, the work highlights the advantages, complexity and technical compatibility in a development project. This research retains only the "relative advantage" component as a characteristic attribute of an ERP innovation. This choice is explained, firstly, by the desire to simplify the ERP adoption model and, secondly, by the fact that the results of previous studies that have dealt with the adoption of this organizational innovation have concluded that only the "benefit provided" was a determinant of adoption [21] [10]. Thus, the main benefits identified were technical, operational, strategic, and organizational [22]. The technical benefits are primarily related to the capabilities of the IT infrastructure [23]. IT infrastructure is the basis and support for computer applications and, consequently, the prerequisite and determinant of any type of benefit provided by an IS [24]. This benefit (measured in terms of improving the capabilities of the IT infrastructure) would condition, in other words, the other benefits. It must, therefore, be considered as the one that is at the origin of the choice of an ERP innovation, and that leads to its adoption. The perceived characteristics of the innovation are therefore introduced into the modeling of ERP success in terms of "improving the capabilities of the IT infrastructure".

To summarize, the links between these two theoretical frameworks, supporting the premises of this work, find their justification in the work carried out by the RBV school "from a resource-based view of IT success evaluation" [25]. This posits, in a governance meta-model involving strategic technological and organizational resources, value-creating interactions. In this sense, it constitutes a conceptual aid for the analysis of IT adoption by considering the simultaneous effects of innovation and the integration of IT in an intermediate process of capacity transformation, as suggested by McKeen et al., [26]. This schema helps to delineate theoretical choices and interactions, and provides a revised framework for evaluating the success of IT. It helps to apprehend and justify the conceptual components in relation to (1) the functionalities of the IT studied, (2) the structural characteristics of the process of its adoption and its applications during its integration into the company's IS, and (3) the methods for evaluating the performance of the IT studied [27] [10]. Nevertheless, this research work will be limited to validating only the relationship between two levels of analysis of the theoretical construction: (1) the determinants of ERP success (technological and organizational); and (2) the success of ERP implementation (via the results induced by its use).

The research model (Fig. 1) establishes the relationships between (1) the key success factors of ERP implementation (prerequisites/precursors); and, (2) the result factors reflecting the benefits of the implementation (performance/success).

The existence of this relationship, established by previous work, is validated by the results of the exploratory study conducted by M.Abdel-hak et al., [27]. The interaction identified during this study between these two factors, which legitimizes a qualitative approach to the phenomenon of ERP adoption, which could for example be proposed for work on change management, i.e. in-situ and during implementation, is impossible to analyze in a context of ad hoc research limited to capturing the phenomenon at a given time. To be generalized, this model requires an empirical study conducted with a representative sample of SMEs, and a test of the data through hypothetico-deductive research. This study leads us to briefly recall, in this paper, the concepts and variables used for each of the two levels of this research model.

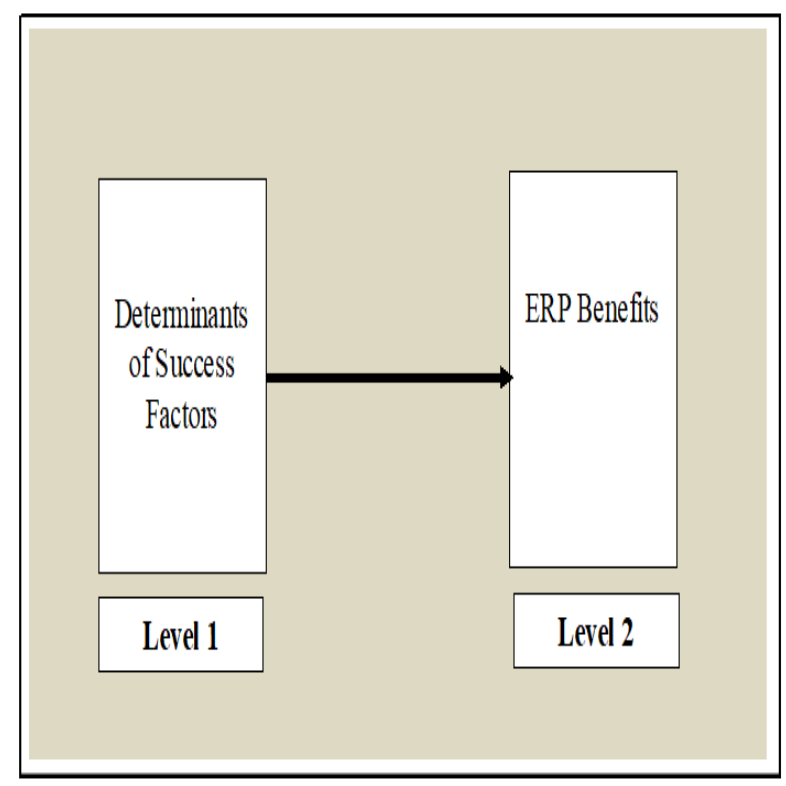

Fig. 1. General Structure of the Research Model.

\section{The CONCEPtUAL MOdel OF RESEARCH}

\section{A. Benefits of Implementing an ERP System}

The results of the scoping study [27] indicate several potential benefits. Only those that appeared to be the most discriminating and that fall within the scope of the evaluation of ERP success. These intangible benefits relate to information literacy and improved skills utilization), and symbolize the improvement of individual capacities to do business in SMEs.

Information literacy is an important concept of ERP success and is the main benefit provided [28]. Previous work shows that one of the most important reasons why organizations adopt an ERP is its ability to facilitate the exchange of information, to solve information fragmentation problems [4], and to satisfy the information needs of all business units [29]. This concept is reflected in the results of the exploratory analysis in terms of availability (BEINFD), reliability (BEINFF), security (BEINFS) and real-time access (BEINFA) to information. These terms refer to variables to be explained in the model, to describe the improvement of the management and control of the information that circulates via the ERP. The comments collected, compared with the results of previous work, also show the organization's ability to control information, as a source of other induced benefits, such as improved decision-making, control, financial performance, productivity, resource and production management. 
Improving skills utilization is an equally important concept of ERP success that should also be considered a significant benefit [23]. This concept is captured by the exploratory analysis in terms of the capabilities provided to employees to develop new and more appropriate management and organizational skills (BECPMT), as well as to promote better use of certain management tools and techniques (BECPTG). These terms refer to as many variables to be explained in the model measuring an improvement in the management of human resources, a source of wealth creation, but also a source of significant expenditure. This is why the optimal exploitation of employees' potential remains a permanent concern for companies. The results of previous work show that an ERP offers employees the opportunity to detach themselves from routine and repetitive tasks, and to concentrate on analytical tasks with more added value. The new business practices and the multiple functionalities offered by this IT also provide employees with the tools they need to better master procedures and develop their skills.

The success of an ERP implementation is evaluated, to summarize, by two conceptually independent levels of apprehension. The first, that of "information control" is the subject of four variables to be explained, measuring the efficiency of the management system impacted by information control. The second, that of "use of skills" is the subject of two variables to be explained, measuring the transformation and improvement induced in skills by the "fit" between work and IT.

\section{B. Determinants or Organizational Capacities for Success}

The results of the scoping study point to several key success factors, the most significant of which are the quality of the project team, the definition of the project team's mission, user training, user acceptance, commitment from senior management, business process re-engineering and selection of the ERP provider [27].

The quality of the project management team is a key concept in the success of an ERP implementation [30]. Previous work shows that a quality project team is a wellbalanced, experienced team composed of qualified people [31], trained and led by a confirmed project manager. This concept is reflected in the results of the exploratory analysis in terms of the composition (DSEPCE) and competence (DSEPCQ) of the team.

The definition of the project management team's mission is a concept frequently cited as a determinant of success in ERP projects [32]. This concept is here unidimensional and is measured (DSEPME), reflecting the quality of ERP implementation project planning. It should be remembered that, in terms of ERP, the plan specifies the roles of the stakeholders and specifies the field of investigation, as well as the objectives of the project at these different stages.

User acceptance is also a concept frequently cited as a determinant of the success of ERP projects [33] [34]. This concept is here unidimensional and is measured (DSACCP), reflecting the fact that if users do not initially accept the system wholeheartedly, then senior management imposes constraints. Users are then forced to cooperate and deal with the system.
The lack of user training refers to a concept frequently cited as a cause of problems in ERP implementations [32]. This concept is one-dimensional and is measured (DSFORM), reflecting the fact that user participation in training sessions is necessary to operate the software package effectively. It should be remembered that, in ERP, training produces knowledge for all the functionalities and modules to be implemented.

The commitment of senior management refers to a concept that has been well identified, through work on IS planning, as a determinant of the success of IT, and therefore ERP, acceptance [32]. This concept is unidimensional and is subject to measurement (DSDGEN) with specific attributes that are important, primordial, strategic, philosophical, stimulating and driving. These terms are often used in the words of ERP project stakeholders to describe the role and commitment of senior management in the implementation process.

The Business Process Review refers to a generic concept (the BPR) that is always mentioned as an explicit condition for successful IS integration and e makes ERP implementation a success [35]. This concept is one-dimensional and is measured (DSRPA), which shows that the objective of this reconfiguration is generally to adapt the ERP to the solution desired by the customer, adapt the company's processes to the software package's standards, and improve business process performance.

The selection of the ERP solution refers to a concept, globally evaluating the quality and appropriation of the tender documents, which strongly conditions the success of ERP projects [32]. This concept is rendered by the results of the exploratory analysis in terms of the selection of the appropriate software package (DSFRCH) and the supplier/company relationship (DSFRRL). These terms are the subject of two different explanatory variables that measure: for the first, the fact that the ERP meets the organization's needs and the coverage of its processes, on which the success of its implementation and use will depend. The exploratory analysis shows, in this sense, that the majority of companies proceed, at the beginning of the project, to the elaboration of specifications based on an analysis of the needs and the offer on the market of ERP software packages. For the second, the fact that the supplier/enterprise relationship is vital to the success of the project [36]. The exploratory analysis also shows that the establishment of a trusting and serious relationship between the buyer and the ERP supplier is recommended for the successful conduct of the project.

\section{THE MOdEL AND ResEARCH Hypothesis}

The conceptual model (Fig. 2) supports, via a hypotheticaldeductive approach, a systemic analysis framework designed to test the simultaneous influence of critical success factors (organizational capabilities) on the benefits of ERP implementation (business/managerial capabilities). The proposed deterministic framework, justified by previous exploratory work [27], assumes the existence of a network of direct causalities between endogenous and exogenous variables at both conceptual levels. 
This empirical approach, conducted among SMEs that have implemented an ERP in recent years, postulates the existence of direct influential relationships between the variables of the system under study. This empirical study is thus intended to test a single general research hypothesis, which formulates the "fit" of the structure of the linear relations (R1) between the variables of the control model and the data. This "fit" is intended to identify an optimal model, from the only significant pathways between the endogenous and exogenous variables of the two conceptual levels (1 and 2).

The general hypothesis supporting this fact is limited, within the framework of this exploratory work, to stating these direct and indirect influences:

HG: The benefits of an ERP system (evaluated by the Level 2 variables) are directly influenced (R1) by organizational capacities (evaluated by the Level 1 variables).

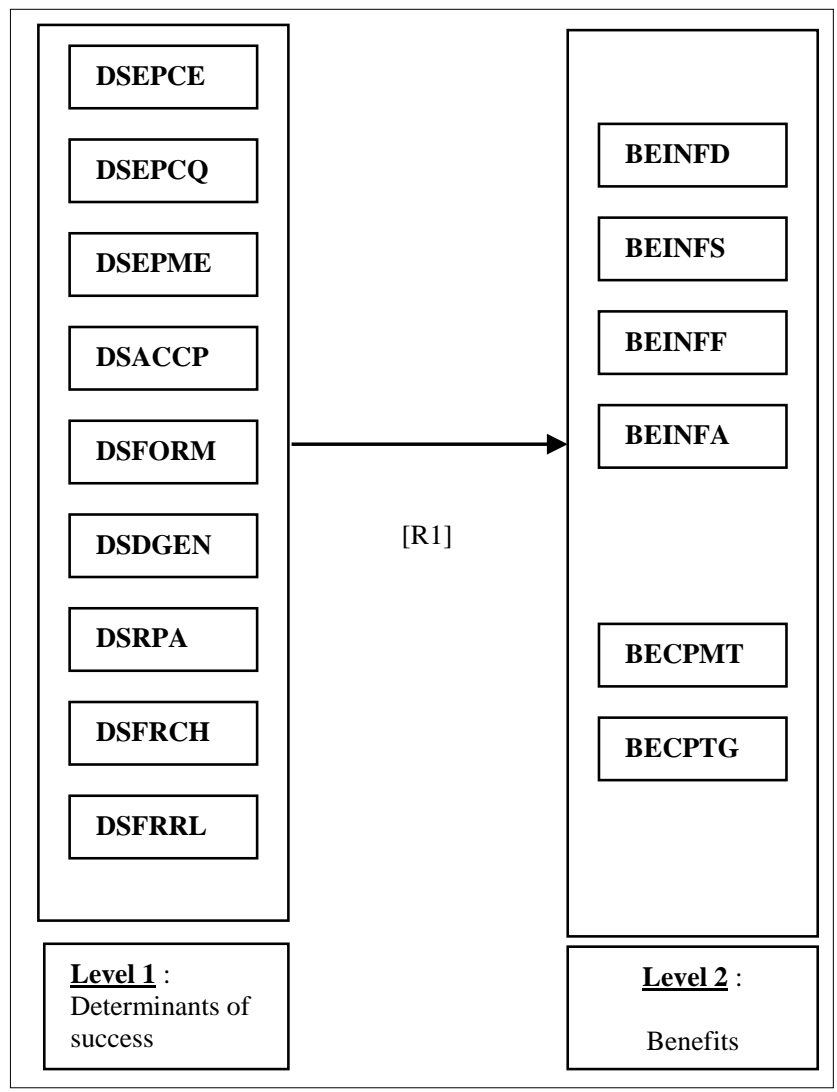

Fig. 2. The Conceptual Model.

\section{The Methodological FrameWORK OF THE RESEARCH}

This study is carried out in the context of Saudi SMEs, which have opted for an ERP solution over the last decade. All the companies in the sample, 92 in all, are in a postimplementation phase of this IT at the time of the study, and are able to evaluate, ex-post, the conditions of implementation and the benefits of its use.

The practice evaluation questionnaire was developed based on the exploratory study [27] and a review of existing metrics in the literature in order to adapt them to the measurement of the research variables. This report presents two parts relating to the two components of the conceptual model. For each of these components, the concepts, variables and constructs are stated. Each construct is the subject of an item coding and a 5point Lickert scale.

The questionnaire was administered to people who were both active members of the ERP project team and members of the general management, with a certain preference for the directors of information systems. Targeted individuals (such as CEOs, production, procurement, or sales managers) were expected to be involved in all phases of the project.

The treatment of the research problem is approached using a structured methodology using conjugation (justified by the low number of cases), and a sequence of 1st generation descriptive methods (such as principal component analysis (PCA) and the reliability test of constructs) and 2nd generation explanatory methods (such as structural equations and dependency analysis) with SPSS and AMOS.

\section{The Results Of THE RESEARCH}

The results of the treatments carried out concern, for the variables of the model, the descriptive analysis intended to check the validity (convergent and discriminant) and the reliability of the constructs (Cronbach's "alpha" coefficients calculated for the items in the questionnaire. The results of the treatments for the HG test concern the study of the significance of the general fit of the model to the data and the study of the direct and indirect pathways between variables of the model.

TABle I. The Results of the Reliability Test: $(\alpha)$ Cronbach

\begin{tabular}{|c|c|c|c|}
\hline & Factors & Items & $\begin{array}{l}\text { Alpha } \\
(\alpha)\end{array}$ \\
\hline \multirow{12}{*}{ 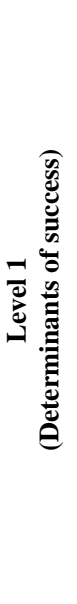 } & DSEPCE & Dsepce1,Dsepce2,Dsepce3 & 0,7023 \\
\hline & DSEPCQ & Dsepcq1,Dsepcq2,Dsepcq3,Dsepcq4 & 0,6979 \\
\hline & DSEPME & Dsepme1,Dsepme2,Dsepme3 & 0,7735 \\
\hline & DSACCPF1 & Dsaccp2, Dsaccp3, Dsaccp4 & 0,9070 \\
\hline & DSACCPF2 & Dsaccp5,Dsaccp6,Dsaccp7 & 0,8227 \\
\hline & DSFORM & Dsform1,Dsform2,Dsform3,Dsform4 & 0,6943 \\
\hline & DSDGENF1 & Dsdgen1,Dsdgen2,Dsdgen5 & 0,8132 \\
\hline & DSDGENF2 & Dsdgen3, Dsdgen4, Dsdgen5 & 0,6917 \\
\hline & DSRPA & Dsrpa1,Dsrpa2,Dsrpa3,Dsrpa4 & 0,8506 \\
\hline & DSFRCHF1 & Dsfrch1,Dsfrch2,Dsfrch5,Dsfrch6 & 0,8558 \\
\hline & DSFRCHF2 & Dsfrch3, Dsfrch4 & 0,5281 \\
\hline & DSFRRL & Dsfrrl1,Dsfrrl2,Dsfrrl3,Dsfrrl4 & 0,8624 \\
\hline \multirow{6}{*}{ 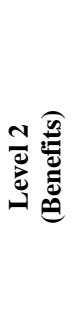 } & BEINFD & Beinfd1, Beinfd2, Beinfd3 & 0,7468 \\
\hline & BEINFS & Beinfs1, Beinfs2, Beinfs3 & 0,7355 \\
\hline & BEINFF & Beinff1, Beinff2, Beinff3 & 0,7880 \\
\hline & BEINFA & Beinfa1,Beinfa2,Beinfa4 & 0,8140 \\
\hline & ВECPMT & $\begin{array}{l}\text { Becpmt1, Becpmt3, Becpmt4, Becpmt5, } \\
\text { Becpmt6 }\end{array}$ & 0,8450 \\
\hline & BECPTG & Becptg1, Becptg2, Becptg3 & 0,8436 \\
\hline
\end{tabular}


TABLE II. CONVERGENT VALIDITY OF ONE-DIMENSIONAL CONSTRUCTS

\begin{tabular}{|c|c|c|}
\hline \multirow{5}{*}{ DSFORM } & Items & 1 \\
\hline & $\begin{array}{l}\text { Dsform1 } \\
\text { Dsform2 } \\
\text { Dsform3 } \\
\text { Dsform4 }\end{array}$ & $\begin{array}{l}, 739 \\
, 814 \\
, 694 \\
, 655\end{array}$ \\
\hline & Eigenvalues & 2,119 \\
\hline & Explained variance & $52,966 \%$ \\
\hline & Cumulative variance & $52,966 \%$ \\
\hline \multirow{5}{*}{ DSRPA } & Items & 1 \\
\hline & $\begin{array}{l}\text { Dsrpa1 } \\
\text { Dsrpa2 } \\
\text { Dsrpa3 } \\
\text { Dsrpa4 }\end{array}$ & $\begin{array}{l}, 761 \\
, 860 \\
, 840 \\
, 879\end{array}$ \\
\hline & Eigenvalues & 2,795 \\
\hline & Explained variance & $69,883 \%$ \\
\hline & Cumulative variance & $69,883 \%$ \\
\hline \multirow{5}{*}{ DSEPCE } & Items & 1 \\
\hline & $\begin{array}{l}\text { Dsepce1 } \\
\text { Dsepce2 } \\
\text { Dsepce3 }\end{array}$ & $\begin{array}{l}, 684 \\
, 794 \\
\text {,905 }\end{array}$ \\
\hline & Eigenvalues & 1,918 \\
\hline & Explained variance & $63,918 \%$ \\
\hline & Cumulative variance & $63,918 \%$ \\
\hline \multirow{5}{*}{ DSEPME } & Items & 1 \\
\hline & $\begin{array}{l}\text { Dsepme1 } \\
\text { Dsepme2 } \\
\text { Dsepme3 }\end{array}$ & $\begin{array}{l}, 831 \\
, 782 \\
, 880 \\
\end{array}$ \\
\hline & Eigenvalues & 2,076 \\
\hline & Explained variance & $69,202 \%$ \\
\hline & Cumulative variance & $69,202 \%$ \\
\hline \multirow{5}{*}{ DSEPCQ } & Items & 1 \\
\hline & $\begin{array}{l}\text { dsepcq1 } \\
\text { dsepcq2 } \\
\text { dsepcq3 } \\
\text { dsepcq4 }\end{array}$ & $\begin{array}{l}, 782 \\
, 588 \\
, 785 \\
, 746 \\
\end{array}$ \\
\hline & Eigenvalues & 2,131 \\
\hline & Explained variance & $53,271 \%$ \\
\hline & Cumulative variance & $53,271 \%$ \\
\hline
\end{tabular}

A. Content Validity of the Research Variables

1) Variable content validity - organizational capabilities (Level 1): Each construct measuring a variable or determinant of ERP success at the first conceptual level is subject to a validity test with a principal component analysis (PCA) and a reliability test.

The principal component analysis (PCA) of the attributes of the "user training" (DSFORM), "business process reengineering" (DSRPA) and "project team mission" (DSEPME) constructs shows the existence of a onedimensional factorial structure. The dimension extracted by the principal component analysis (PCA) has an eigenvalue equal to 2.076 and restores an explained variance higher than
$69 \%$. The factorial contributions of the measurement items are greater than 0.654 . The reliability of this construct is confirmed. (Table I)

The quality of the project team is assessed by two variables measuring the composition of the project team (DSEPCE) and the capacity of the project team (DSEPCQ). principal component analysis (PCA) of the attributes of the first construct measuring "the composition of the project team" and "the capacity of the project team" verify their unidimensionality. The extracted factor has an eigenvalue greater than 1.918 and returns an explained variance greater than $53.271 \%$. The factorial contributions of the three measurement items are greater than 0.60 (Table II). The reliability of these constructs is confirmed (Table I).

The principal component analysis (PCA) of the attributes of the constructs "user acceptance" (DSACCP) and "management commitment" (DSDGEN) shows the presence of a factor structure with two independent components. These extracted factors jointly restore an explained variance greater than $74.042 \%$ and each has an eigenvalue greater than 1 . For the rest of the study, the "Dsaccpf2" factor is retained as an effective measure of user acceptance, while the "Dsaccpf1" factor is retained as a measure of ease of use. Similarly, the "dsdgenf1" factor was chosen as an effective measure of the involvement of the general management, while the "dsdgenf2" factor was chosen as a measure of the general management's intervention (Table III). The reliability of these two constructs is confirmed (Table I).

The selection of the ERP solution is measured by two supposedly independent variables, "the selection of the ERP software package (DSFRCH)" and "the quality of the company/supplier relationship (DSFRRL)".

TABLE III. CONVERGENT VALIDITY OF TWO-COMPONENT CONSTRUCTIONS

\begin{tabular}{|c|c|c|c|}
\hline \multirow{5}{*}{ DSACCP } & Items & Dsaccpf1 & Dsaccpf2 \\
\hline & $\begin{array}{l}\text { Dsaccp1 } \\
\text { Dsaccp2 } \\
\text { Dsaccp3 } \\
\text { Dsaccp4 } \\
\text { Dsaccp5 } \\
\text { Dsaccp6 } \\
\text { Dsaccp7 }\end{array}$ & $\begin{array}{l}\text { 438 } \\
\text { 852 } \\
\text {,928 } \\
\text { 895 }\end{array}$ & $\begin{array}{l} \\
, 782 \\
, 836 \\
, 849 \\
\end{array}$ \\
\hline & Eigenvalues & 3,850 & 1,333 \\
\hline & Explained variance & $55 \%$ & $19,042 \%$ \\
\hline & Cumulative variance & $55 \%$ & $74,042 \%$. \\
\hline \multirow{5}{*}{ DSDGEN } & Items & Dsdgenf1 & Dsdgenf2 \\
\hline & $\begin{array}{l}\text { Dsdgen1 } \\
\text { Dsdgen2 } \\
\text { Dsdgen3 } \\
\text { Dsdgen4 } \\
\text { Dsdgen5 }\end{array}$ & $\begin{array}{l}, 868 \\
, 906 \\
\\
\\
, 785\end{array}$ & $\begin{array}{l}\text {,846 } \\
\text {,800 } \\
\text { 784 }\end{array}$ \\
\hline & Eigenvalues & 2,090 & 1,809 \\
\hline & Explained variance & $41,797 \%$. & $36,189 \%$ \\
\hline & Cumulative variance & $41,797 \%$ & $77,986 \%$ \\
\hline
\end{tabular}


The Principal Component Analysis (PCA) of the attributes of the first construct "selection of the ERP software package" shows the presence of a two-dimensional factor structure. The items have high contributions on the two extracted factors (> 0.80 ). The first factor "Dsfrchf1", obtained from attributes 1 , 2, 5 and 6, is retained as an effective measure of the project requirement, with a high eigenvalue of 2.823, restores an explained variance of $47.054 \%$. The second factor "Dsfrchf2", obtained from items 3 and 4 , is retained as a measure of the adaptation of the offer, with an eigenvalue of 1.459 , restores an explained variance of $24.320 \%$. The cumulative variance of these two factors is $71.374 \%$ (Table IV). The reliability of these two constructs is confirmed (Table I).

The principal component analysis (PCA) of the attributes of the second construct measuring the "quality of the company/supplier relationship" shows the presence of a onedimensional factorial structure. The factorial contributions of these measurement items are greater than 0.769 . The extracted dimension has a high eigenvalue of 2.853 and returns 71.313 $\%$ of explained variance.

2) Content validity of the variables to be explained managerial skills (Level 2): The second conceptual level refers to two multidimensional concepts related to "information literacy" and "skills use".

The concept of "information literacy" is assessed by the variables BEINFD, BEINFS, BEINFF, BEINFA. The four constructs are measured by twelve attributes. The principal component analysis (PCA) of these attributes gives four factors. The factorial contributions, higher than 0.558 , on the four factors returned (Table V) are all significant.

The concept of "best use of skills" is assessed through the variables BECPMT, BECPTG. Both constructs are measured by eight attributes. The principal component analysis (PCA) of these attributes restores two factors. The factorial contributions, higher than 0.602 , on the two restituted factors (Table VI) are all important.

\section{B. Testing the General Hypothesis HG}

The purpose of this test is to validate the general structure of the control model. It is carried out by studying, firstly, the "fit" of the general model and, secondly, the paths in an optimal model rejecting the path coefficients between variables to be explained and non-significant explanatory variables ( $>5 \%)$.

The evaluation of the quality of the fit of the model to the data consists in estimating the quality of the fit of the theoretical model to the empirical data. This step (in particular the analysis of the precision indices of the global model) uses a combination of indices with different characteristics (absolute, incremental and parsimony indices). The analysis of the values of these indices indicates acceptable results; the model is "over-identified" (the degree of freedom (ddl) is equal to 120 and therefore strictly positive) and the set of indices respects the limit values suggested by the literature on the structural equation method (Table VII).

The analysis of the quality of fit, with these indices (Table VI), shows an excellent fit ( $\mathrm{p}=88.4 \%$ ) of the proposed model to the data, as well as a very small impact of residuals on the model (5.6\%). The general assumption regarding the overall structure of the model and in particular the presence of causal effects between the different explanatory and explanatory variables of the model is thus generally accepted. It is therefore possible to state that the benefits of an ERP system are directly influenced by the key success factors of the ERP implementation.

TABLE IV. CONVERgent VALIDITY OF THE CONSTRUCTED "SELECTION OF THE ERP SOFTWARE PACKAGE"

\begin{tabular}{|c|c|c|c|}
\hline \multirow{5}{*}{ DSFRCH } & Items & Dsfrchf1 & Dsfrchf2 \\
\hline & $\begin{array}{l}\text { Dsfrch1 } \\
\text { Dsfrch2 } \\
\text { Dsfrch3 } \\
\text { Dsfrch4 } \\
\text { Dsfrch5 } \\
\text { Dsfrch6 }\end{array}$ & $\begin{array}{l}, 821 \\
, 859 \\
\\
\\
, 780 \\
, 863 \\
\end{array}$ & $\begin{array}{l}\text {,804 } \\
\text { 813 }\end{array}$ \\
\hline & Eigenvalues & 2,823 & 1,459 \\
\hline & Explained variance & $47,054 \%$ & $24,320 \%$ \\
\hline & Cumulative variance & $47,054 \%$ & $71,374 \%$ \\
\hline \multirow{5}{*}{ DSFRRL } & Items & 1 & \\
\hline & $\begin{array}{l}\text { Dsfrrl1 } \\
\text { Dsfrrl2 } \\
\text { Dsfrrl3 } \\
\text { Dsfrrl4 }\end{array}$ & $\begin{array}{l}, 864 \\
, 888 \\
, 769 \\
, 851\end{array}$ & \\
\hline & Eigenvalues & 2,853 & \\
\hline & Explained variance & $71,313 \%$ & \\
\hline & Cumulative variance & $71,313 \%$ & \\
\hline
\end{tabular}

TABLE V. DISCRIMINATORY VALIDITY OF THE CONCEPT OF INFORMATION LITERACY

\begin{tabular}{|l|l|l|l|l|}
\hline \multirow{2}{*}{ Items } & \multicolumn{3}{|c|}{} \\
\cline { 2 - 5 } & BEINFD & BEINFS & BEINFF & BEINFA \\
\hline BEINFD1 & & & & \\
BEINFD2 & & & & \\
BEINFD3 & & & & \\
BEINFS1 & & & & \\
BEINFS3 & &, 558 & & \\
BEINFS4 & &, 851 &, 754 & \\
BEINFF1 & &, 805 &, 616 &, 892 \\
BEINFF2 & & &, 884 &, 727 \\
BEINFF3 &, 828 & & &, 672 \\
BEINFA1 &, 840 & & & \\
BEINFA2 &, 705 & & & \\
BEINFA4 & & & & \\
\hline
\end{tabular}

TABLE VI. DiscRiminatory VALIDITY OF THE BETTER USE OF SKILLS CONCEPT

\begin{tabular}{|l|l|l|}
\hline \multirow{2}{*}{ Items } & \multicolumn{2}{|c|}{} \\
\cline { 2 - 3 } & BECPMT & BECPTG \\
\hline BECPMT1 & & \\
BECPMT3 &, 644 & \\
BECPMT4 &, 875 & \\
BECPMT5 &, 602 & \\
BECPMT6 &, 762 &, 888 \\
BECPTG1 &, 805 &, 910 \\
BECPTG2 & &, 661 \\
BECPTG3 & & \\
\hline
\end{tabular}


TABLE VII. PRECISION INDICES FOR THE GENERAL MODEL

\begin{tabular}{|l|l|l|l|}
\hline & $\begin{array}{l}\text { Precision } \\
\text { indices }\end{array}$ & $\begin{array}{l}\text { Calculated } \\
\text { values }\end{array}$ & $\begin{array}{l}\text { Recommended } \\
\text { values }\end{array}$ \\
\hline \multirow{4}{*}{$\begin{array}{l}\text { Absolute } \\
\text { indices }\end{array}$} & Chi-Deux $\left(\chi^{2}\right)$ & 96,4 & \\
\cline { 2 - 4 } & $\mathrm{P}\left(\chi^{2}=96,4\right)$ & $\mathbf{8 8 , 4 0} \%$ & $>10 \%$ \\
\cline { 2 - 4 } & $\mathrm{ddl}$ & 120 & \\
\cline { 2 - 4 } & $\chi^{2 / \mathrm{ddl}}$ & $\mathbf{0 , 7 3 8}$ & $<5$ \\
\cline { 2 - 4 } & GFI & $\mathbf{0 , 8 9 8}$ & $>0,9$ \\
\cline { 2 - 4 } & AGFI & 0,873 & $>0,9$ \\
\cline { 2 - 4 } & RMR & $\mathbf{0 , 0 4 6}$ & $<0,1$ \\
\cline { 2 - 4 } & RMSEA & $\mathbf{0 , 0 0 0}$ & $<0,08$ \\
\hline \multirow{2}{*}{$\begin{array}{l}\text { Incremental } \\
\text { indices }\end{array}$} & NFI & 0,883 & $>0,9$ \\
\cline { 2 - 4 } & CFI & 1,000 & \\
\hline \multirow{2}{*}{$\begin{array}{l}\text { Parsimony } \\
\text { indices }\end{array}$} & PNFI & 0,618 & \\
\cline { 2 - 4 } & PGFI & 0,643 & \\
\hline
\end{tabular}

The validation of HG also requires the verification of the significance of the dependency model parameters and the determination coefficients $\left(\mathrm{R}^{2}\right)$ of the variables to be explained of the ERP implementation benefit.

Analysis of the regression coefficients shows that the direct dependency relationships are significant at the risk threshold $\mathrm{p}<5 \%$. These relationships reflect a high determinism of the influence of the explanatory variables on the ERP implementation result variables.

The determination coefficients $\left(\mathrm{R}^{2}\right)$ of the dependent variables are high and significant $(\mathrm{P}<1 \%)$. Indeed, 39.2\% of the variance of the information availability variable "BEINFD", $70.2 \%$ of the variance of the information security variable "BEINFS", 57.3\% of the variance of the information reliability variable "BEINFA", $64.2 \%$ of the variance of the information reliability variable "BEINFF", $75.3 \%$ of the variance of the variable "BECPMT" and $69.4 \%$ of the variance of the variable "BECPTG" are explained by the causal model HG.

Thus, the results relating to the "fit" of the model and the explained variance of the dependent variables validate the structure of the model tested. The optimal model that supports the HG hypothesis (representing the only significant dependency relationships identified at the significance level $<5 \%)$ is established by the following relationship diagram (Fig. 3).

The pathway analysis performed for these only significant pathways ( $<<5 \%$ ) partially confirms the HG hypothesis. The pathway study reveals the main dependency relationships between the benefit variables of an ERP system (Level 2), and the key success factors (Level 1). The results of the pathways study carried out on the direct dependency relationships allow us to confirm globally the hypotheses of direct influences of organizational and technological capacities on managerial capacities for information management and improvement of the use of skills (Table VIII).

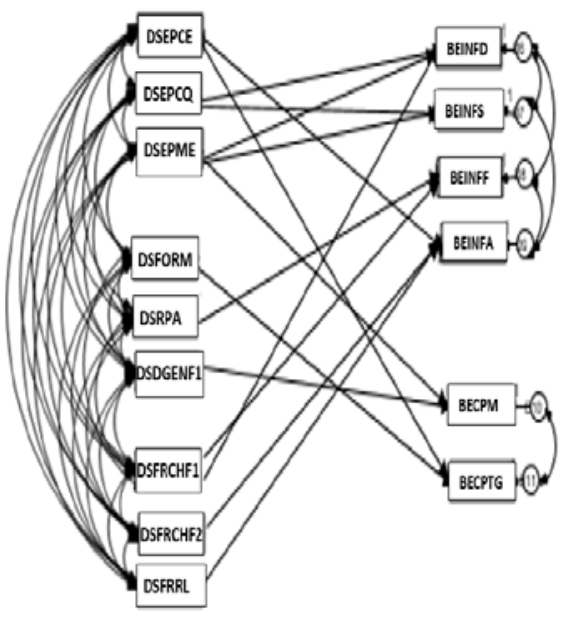

Fig. 3. The Optimal Control Model HG.

TABLE VIII. TESTING OF ADJACENT RESEARCH HyPOTHESES

\section{Hypotheses}

The composition of the project team DSEPCE has a positive impact on the four dimensions of information mastery (availability (BEINFD), reliability (BEINFF), security (BEINFS) and access (BEINFA)).

The composition of the DSEPCE project team has a positive impact on improving the use of skills (BECPMT).

The composition of the project team DSEPCE has a positive impact on improving the use of certain management tools and techniques (BECPTG).

The capacity of the project team (DSEPCQ) has no influence on the availability of information (BEINFD)

The composition of the project team (DSEPCE) as a positive impact on improving the use of skills.(BECPMT)

The mission of the project team (DSEPME) has a positive impact on information security and access to information ("BEINFS", "BEINFA").

The mission of the project team (DSEPME) has a positive impact on improving the use of skills (BECPMT).

Training (DSFORM) has a positive impact on the availability of information (BEINFD).

Training (DSFORM) has a direct positive impact on improving the use of management tools and techniques (BECPTG).

Business process reengineering (DSRPA) has a positive impact on the four dimensions of information mastery (BEINFD, BEINFS, BEINFA, BEINFF)

Business Process Re-engineering (DSRPA) has a positive impact on both dimensions of skills utilization improvement ("BECPMT", "BECPTG").

The requirement of the ERP project "DSFRCHF1" has a positive impact on the four dimensions of information mastery ("BEINFD", "BEINFS", "BEINFA", "BEINFF")

The requirement of the ERP project "DSFRCHF1" has a positive impact on both dimensions of skills utilization improvement ("BECPMT", "BECPTG").

The adaptation of the ERP offer (DSFRCHF2) has a positive impact on access to information (BEINFA).

The company/ERP supplier relationship (DSFRRL) has a positive impact on the access to information (EINFA).

The company/ERP supplier relationship (DSFRRL) has a positive impact on the new management and organizational skills (BECPMT).

The involvement of senior management in the management of resources (DSDGENF1) has a negative influence on access to information (BEINFA).

The intervention of the general management (DSDGENF2) has no influence on the ERP benefits.

User acceptance of (DSACCP) has no influence on the benefits of ERP implementation. 


\section{DISCUSSION OF THE RESULTS}

The results obtained from the path analysis of the optimal search model lead to different conclusions regarding the determinants of ERP success:

The "quality of the project team" is one of the most decisive factors for ERP success. Companies planning to implement an ERP system need to ensure that they have a balanced project team (a combination of both technical and managerial skills) with the knowledge, talent, and experience to handle the length and complexity of the task [37].

The positive impact of project team composition on information literacy is due to the dual skills (technical and managerial) of the project team. This mix of skills facilitates the understanding and technical formulation of users' information needs. This is a necessary step in the operation of parameterizing the ERP system and is important for improving information sharing [38] and availability [39].

The positive impact of the project team's composition on improving the use of skills also shows that when the team is balanced, the choices relating to the parameterization operation (the functionalities to be used), to the management of access to the system's applications, better meet the needs of users and better promote the use of talents and experience.

The definition of the "mission of the project team" is essential for the proper conduct of the ERP project. Specifying the role of each party involved in the project (at contract or specification level, even before the call for tenders is issued) makes it possible to establish the responsibilities and rights of each party [40]. The precision of the objectives of the ERP project also makes it possible to achieve the benefits expected from the implementation of the ERP system.

Business process re-engineering" is necessary to achieve (directly and/or indirectly) the projected benefits of implementing ERP systems [41]. The incompatibility of the characteristics of ERP software packages with the organization's business processes and the IT infrastructure in place may be the source of problems in implementing the ERP system. It is imperative for the success of ERP system implementations that the ERP implementation be preceded, therefore, by a review of the content of the functions, processes, tasks and IT infrastructure in place [39]. The objective of this reconfiguration is generally to respond to the solution desired by the client, to adapt processes to the standards of the ERP software package and/or to optimize the use of the ERP's functionalities.

The impact of reengineering on the use of new management tools and techniques is explained by the effect of "Best Practices" and the rich range of functionalities incorporated in ERPs. The business processes, incorporated in the ERP, are the result of long experience and benchmarking operations in different economic sectors. They embody the best business practices that can generate a competitive advantage for those who adopt it [42]. For many companies, complying with these rules and procedures translates into significant productivity gains [4].
The positive impact of reengineering on improving employee work control is due to the revision of the content of their functions and tasks. The standardization of company processes means that users are obliged to improve their old management and organizational practices.

The positive impact of re-engineering on the improvement of information control is due to the rationalization of the IT platform. This standardized platform allows a diverse use of information (e.g. summarized, aggregated, condensed data from several information sources within the company). Upgrading the IT infrastructure usually results in the replacement of transactional file systems or disparate databases with a single relational database system. These RDBMSs allow for better data management and manipulation.

User training" is a prerequisite for the success of the ERP project. The participation of users in training sessions is necessary for the efficient operation of the software package. These training actions must be conducted according to a clear program that is capable of meeting the expectations of the users. It is also recommended that training be carried out on all the functionalities and modules to be implemented for a better appreciation of the functional links generated by the integration. Lack of user training frequently appears to be responsible for problems in implementing ERP systems [43].

The positive impact of training on the availability of information is explained by the fact that the training provided on the various functionalities of the ERP system allows ERP users to be much more autonomous with regard to information. The training focuses on the possibilities offered by the new system to each user to have and use the information he needs, from his workstation.

The positive impact of training on improving the use of BECPTG management tools and techniques shows that training can benefit employees through the acquisition of certain management and organizational skills. The training allows employees to make better use of certain management tools and techniques, such as "dashboards, simulation techniques" incorporated into the system, to practice "international management", to "break away from routine tasks, focus on business aspects and move on to analytical tasks".

The "selection of an ERP solution" appropriate to the company's needs is a condition for the success of ERP projects [44]. KSA companies call on the services of their ERP suppliers to help them implement the system they have acquired. In this case, they are called upon not only to seek out the software package that best suits their needs, but also to ensure the choice of a supplier with the human resources necessary for the proper conduct of the project.

The precision of the "ERP project requirements" for the choice of a better ERP solution is an important factor for success. Before acquiring an ERP system, companies generally carry out a needs analysis and an analysis of the offer on the market for ERP software packages. Choosing the wrong software package can mean committing to an IT architecture and applications that do not fit the organization's 
objectives [45] or business processes and therefore limits the chances of ERP success.

The positive impact of training on improving the use of BECPTG management tools and techniques shows that training can benefit employees through the acquisition of certain management and organizational skills. The training allows employees to make better use of certain management tools and techniques, such as "dashboards, simulation techniques ..." incorporated into the system, to practice "international management", to "break away from routine tasks, focus on business aspects and move on to analytical tasks".

The "selection of an ERP solution" appropriate to the company's needs is a condition for the success of ERP projects [44]. Tunisian companies call on the services of their ERP suppliers to help them implement the system they have acquired. In this case, they are called upon not only to seek out the software package that best suits their needs, but also to ensure the choice of a supplier with the human resources necessary for the proper conduct of the project.

The precision of the "ERP project requirements" for the choice of a better ERP solution is an important factor for success. Before acquiring an ERP system, companies generally carry out a needs analysis and an analysis of the offer on the market for ERP software packages. Choosing the wrong software package can mean committing to an IT architecture and applications that do not fit the organization's objectives [45] or business processes and therefore limits the chances of ERP success.

\section{CONCLUSION}

The results of the analyses designed to test the partial hypotheses of dependence, confirm the existence of a general structure of the research model at two conceptual levels, and verify the general hypothesis in its generality. It should be noted that the general hypothesis is generally accepted and, consequently, that the benefits of using an ERP are influenced by the key success factors of the ERP implementation. Aside from the intervention of general management and user acceptance, which have no effect on the success of ERP implementation, the analysis has validated the benefits and the FCS identified during the exploratory study [27].

The spin-offs of this research work concern the development of companies. They are both beneficial for those who have already adopted an ERP system, but also for those who plan to acquire and implement such a tool. For the first category, a framework for evaluating the success of the ERP project is developed. This framework makes it possible to justify this investment by evaluating its benefits. For the second category, a coherent framework of ERP appropriation based on the experience of the first ones is formulated and to take advantage of it (based on the results of this work). Indeed, companies can expect to improve their performance and reap the benefits of an ERP implementation, knowing that achieving this objective is conditioned by a number of key success factors that determine the benefits of implementing an ERP. These key success factors are identified in this work in order to contribute to better planning and management of this type of project. These contributions provide the opportunity, among other things, to propose means of action (direct and indirect) relating to the determining factors of ERP success.

On the theoretical level, while helping to validate some theoretical and conceptual results of previous work, this work contributes to a better understanding of the success of ERP adoption in an emerging country, by proposing a model for evaluating ERP success, according to a systemic approach, thus resembling the necessary governance of ERPs on the strategic objectives of the SMEs studied. This modeling is one of the main contributions of the research because it mobilizes specific research variables that can enrich the modeling of this type of problem.

\section{ACKNOWLEDGMENT}

The researchers extend their thanks and gratitude to the Deanship of Graduate Studies and Scientific Research at Dar Al Uloom University for their support and funding of this study.

\section{REFERENCES}

[1] Laudon, K. C. et Laudon, J. P., Management Information Systems: Managing the Digital Firm. New-York: Prentice Hall, 2018.

[2] EPICOR, 11 Criterions for Selecting the Best ERP System Replacement,http://www.epicor.com/pages/default.aspx, ,2009.

[3] Hakim, A. et Hakim, H., "A Practical Model on Controlling the ERP Implementation Risks”, Information Systems, Vol. 35, $\mathrm{N}^{\circ} 2$, April, 2010, pp. 204-214.

[4] Davenport, T. H., "Mission Critical”, Harvard Business School Press, Boston, Massachusetts, 2000.

[5] Shih-Ya, Y., "The Effect of Computer Self -Efficacy on Enterprise Resource Planning Usage”, Behavior \& Information Technology, 2006, Vol. 25, No. 5.

[6] Chou, S. W. et Chang, Y.C., "The Implementation Factors That Influence The ERP (Enterprise Resource Planning) Benefits”, Decision Support Systems, Vol. 46, N 1, December, 2008, pp. 149-157.

[7] Baile, S. et Trahand, J., "Les systèmes d'information interorganisationnels - contributions et cadre de recherche”, Système d'Information \& Management, Vol. 4, N², 1999, pp. 2-19.

[8] Baile, S. et Mékadmi, S. , La conduite du changement dans un projet ERP: deux retours d'expériences, $11^{\text {ème }}$ Congrès de l'AIM, Luxembourg , 2006 ,.

[9] Baile, S. , Le choix d'une forme de gouvernance organisationnelle des technologies de l'information et de leur succès - Prédictions avec les théories des Coûts de Transaction, du Structuralisme et des Ressources. Papier de Recherche du CERGAM, IAE Aix en Provence. (Soumis au $19^{\text {ème }}$ Congrès AIMS'2010, Luxembourg), 31 pages.

[10] Chatti, H., “Les déterminants du succès d'une implantation d'un ERP dans le contexte tunisien", Thèse de Doctorat en Sciences de Gestion, CRG-IAE, Université de Toulouse 1, Juillet, . 2008, 540 pages.

[11] Schwars, A. et Hirscheim, R. , “An Extended Platform Logic Perspective of IT Governance: Managing Perceptions and Activities of IT, ” Strategic Information Systems, Vol. 12, 2003, pp. 129-166.

[12] Sambamurthy, V. et Zmud, R., "Arrangements for Information Technology Governance: A Theory of Multiple Contingencies, " MIS Quarterly, Vol. 23, N², 1999, pp. 261-290.

[13] Barua, A. et Mukhopadhyay, T., "Information Technology and Firm Performance: Past, Present and Future,” in Zmud, R.W., (Ed.), Framing the Domain of IT Management research: Projecting the Future Through the Past. Pinnaflex Educational Resources, 2000, Cincinnati, OH.

[14] Kerimoglu, O., Basoglu, N. et Daim, T., “Organizational Adoption of Information Technologies: Case of Enterprise Resource Planning Systems”, Journal of High Technology Management Research, Vol. 19, 2008, pp. 21-35. 
[15] Davis, F.D. , "Perceived Usefulness, Perceived Ease of Use and User Acceptance Information Technologies, MIS Quarterly, Vol. 13, 1989, pp. 319-340.

[16] DeLone W.H. et McLean E.R. , "The DeLone and McLean Model of Information Systems Success: a Ten-Year Update”, Journal of Management Information System, Vol. 19 N 4, 2003, pp. 9-30.

[17] Henderson, J. et Venkatraman, N., "Strategic Alignment: Leveraging information technology for transforming organizations”, IBM Systems Journal, Vol. 32, 1993, pp.4-16.

[18] Velcu, O. "'Strategic Alignment of ERP Implementation Stages: An Empirical Investigation”, Information \& Management, (ScienceDirect :Forthcoming), 2010,.

[19] Jouirou, N. et Kalika, M., " l'alignement stratégique : déterminant de la performance - une étude empirique sur les PME ”, 9 $9^{\text {ème }}$ Congrès de l'AIM, Evry, 2004.

[20] Rogers, E.M., Diffusion of Innovations, New -York, Free Press ( $5^{\text {th }}$ Ed), 2003.

[21] Ettien, F.A.K, L'impact individuel des ERP, un axe d'évaluation des changements induits. Thèse de Doctorat en Sciences de Gestion, CRMIAE Toulouse, Université de Toulouse 1-Capitole, Février, 2007,.

[22] Pupion, P.C et Leroux E, "Diffusion des ERP et comportements mimétiques ", $15^{\text {ème }}$ Conférence Internationale de Management Stratégique (AIMS), 2006, Annecy-Genève, Juin.

[23] Shang, S. et Seddon, P.B., A Comprehenive Framework For Classifying the Benefits of ERP Systems, Proceedings of the 2000 Americas Conference on IS, Long Beach California, August 10-08-2000, pp. 1005-1014.

[24] Kumar V et al, , "ERP Systems Implementation: Best Practices in Canadian Government Organizations", Government Information Quarterly, N 19, 2002, pp.147-172.

[25] Wade, M. et Hulland, J. "'The Resource-Based View and Information Systems Research: Review, Extension and Suggestions for Future Research”, MIS Quarterly, Vol. 28, Nº1, 2004, pp. 107-142.

[26] McKeen, J.D., Smith, H.A. et Parent, M., "Assessing the Value of IT: The Leverage Effect", Fourth European Conference on Information Technology, Cork, Ireland, June 21-13, 1997.

[27] M.S Abdel-Haq, H Chatti, E Asfoura,, Investigating the Success and the Advantages of Using ERP System in KSA Context , published by Engineering, Technology \& Applied Science Resea, vol, 8 Issue 6, 2018.

[28] Andreas, I. et Nicolaou, S., "Firm Performance Effects in Relation to the Implementation and Use of Enterprise Resource Planning", Journal of Information Systems, Vol. 18, № 2, 2004, pp. 79-105.

[29] Davenport, T., "Putting the Enterprise into the Enterprise System", Harvard Business Review, Vol. 76, № 4, 1998, pp. 121-131.

[30] Nah, H. et Fui, F. , "Toward a Greater Understanding of End-User's Acceptance of ERP systems", in Kosrow, M. (Ed.): Advanced Topics in Information Resources Management, Vol. 5, 2006, Idea Group Pub.
[31] Nah, F. et Delgado, S., "Critical Success Factors For Enterprise Resource Planning Implementation and Upgrade”, The Journal of Computer Information Systems, Vol. 46, N 55, 2006, pp. 99-113.

[32] Ngai, E. et al., "Examining the Critical Success Factors in the Adoption of Enterprise Resource Planning", Computers in Industry, doi:10.1016/j.compind., 2008.

[33] Netemeyer, R. G., Bearden, W. O. et Sharma, S., Scaling Procedures: Issues and Applications. New-York: Sage Publications, 2003.

[34] Seymour, L. et al., "End-Users Acceptance of Enterprise Resource Planning Systems: An Investigation of Antecedents", Proceedings of the 6th Annual ISONE world Conference, April, 2007, Las Vegas, NV., available at http://www.isoneworld.org.

[35] Malhotra, R. et Temponi, C., "Critical Decisions for ERP Integration: Small Business Issues", International Journal of Information Management, Vol. 30, $\mathrm{N}^{\circ} 1$, February, 2010, pp. 28-37.

[36] Raymond, L. et Uwizeyemungu., S., "A Profile of ERP Adoption in Manufacturing SMEs”, Journal of Enterpnse Information Management, Vol. 20, N 4, 2004.

[37] Wor1ey, J. H., Chatha, K.A., Weston, R.H.., Aguirre, O. et Grabot. B., "Implementation and Optimisation of ERP Systems: a Better Integration of Processes, Roles, Knowledge and User Competencies”, Computers in Industry, Vol. 56, $\mathrm{N}^{\circ}$ 6, 2005, pp 620-638.

[38] Singletary, L, "Empirical Study of Attributes and Perceived Benefits of Applications Integration for Enterprise Systems". PhD Dissertation, Louisiana State University, 2003,

[39] Ehie, I. et Madsen, M., "Identifying Critical Issues in Enterprise Resource Planning (ERP) Implementation”, Computers in Industry, Vol. 56, 2005, pp 545-557.

[40] Parr, A.N., Shanks, G. et Darke, P., "The Identification of Necessary Factors For Successful Implementation of ERP Systems", in O.Ngwenyama, L.D.Introna, M.D.Myers et J.I. De Gross (Eds), New Information Technologies in Organisational Process. Boston: Kluwer Academic Publishers, 1999, pp. 99-119.

[41] Aloini, D., Dulmin, R. et Mininno,V., "Risk Management in ERP Project Introduction: Review of the Literature", Information \& Management, Vol. 44, N 6, September, 2007, pp. 547-567.

[42] Sirigindi Subba Rao, , "Entreprise Resource Planning in ReengineeringBbusiness", Business Process Management Journal, Bradford, 2000.

[43] Nelson K. et Somers T. M., "The Impact of Critical Success Factors across the Stages of ERP Implementations”, Proceedings of the $34^{\text {th }}$ Hawaii International Conference on System Sciences, 2001.

[44] Wu, J.H.; Shin, S.S.; Heng, M.S.H., "A Methodology for ERP Misfit Analysis”; Information \& Management, 44, 2007, pp 666-680.

[45] Robinson et Dilts,, "Or \& ERP : a Match for the New Millennium ?”, ORMS Today, Vol.26, N³, 1999, pp. 30-35. 